\title{
Reforms to Limit Increases in Health Care Expenditures, with Special Attention to the Netherlands
}

\author{
Raymond Gradus \\ VU University Amsterdam, Centre for European Studies \\ Brussels and Research Institute for the CDA Buitenom \\ 18, 2512 XA, Hague, Netherlands \\ E-mail: gradus.wi@cda.nl
}

$\begin{array}{ll}\text { Received: December 29, } 2011 & \text { Accepted: January 30, } 2012 \quad \text { Published: March 1, } 2012 \\ \text { doi:10.5539/res.v4n1p73 } & \text { URL: http://dx.doi.org/10.5539/res.v4n1p73 }\end{array}$

The author would like to thank Evert Jan van Asselt, Mindert Mulder and the participants of a seminar at Fundación FAES in Madrid for their useful comments on an earlier version. This paper has received funding from the European Parliament. This is joint research of the Centre of European Studies and CDA Reseacrh Institute. Sole responsibility for facts or opinions expressed in this publication rests with the author. The Centre for European Studies, the CDA Research Institute and the European Parliament assume no responsibility either for the information contained in the publication or its subsequent use.

\begin{abstract}
In Europe, an ageing population and technological innovation are the most significant drivers behind public health care expenditure increases. Several reforms are needed in order to limit these increases. International research has shown that market mechanisms and better public management have the most effective impact on limiting expenditures. Budget caps can also be important in lowering costs, though they may have some drawbacks. Other instruments, such as supply-side constraints and demand-side reforms, are less effective. Since the 2006 Dutch health care reform, patient orientation within the curative system has improved. However, in order to be able to limit increases in Dutch expenditure, further modifications to the market-orientated health insurance system are needed. For long-term care the recommendation is put forward that ultimately a reform stage should be implemented which would boost the responsibility of individuals and the family and limit the role of the government.
\end{abstract}

Keywords: Health care, Reforms, Ageing Europe, Technology push

\section{Introduction and Questions}

Limiting increases in public health-care expenditures will be a real challenge in Europe in the coming decades. Due to an ageing public, EU health care expenditure is expected to increase by more than 2.5 percentage points of GDP in the next fifty years (see EC (2009a)). This EU-wide average hides substantial disparity among countries. Notably, the cost of Dutch long-term care will rise by 4.5 percentage point GDP and is therefore a great policy challenge. Moreover, this EU projection is based on the assumption that technological innovation does not increase costs. However, in recent years in advanced economies technological innovations have been a more important driver for expenditure increases than ageing. For this reason, IMF projections based on past technological experience are two to three times higher than EU projections (see IMF (2010)).

Nevertheless, the EU projections for public health care spending may still be realistic if several policy reforms are made. In this paper we discuss the impact of such reforms. It appears that introducing market mechanisms and strengthening public management have the most effective impact on increasing efficiency. Budget caps can also be important in lowering costs, though they may have some drawbacks. Other instruments, such as supply-side constraints and demand-side reforms, are less effective, as they are often eroded by supplier responses or tax expenditures. 
In addition, we compare this reform impact analysis with the effects of the 2006 reform of the Dutch curative health care system. From the perspective of the patient, the reform was successful. However, since the beginning of this century there has been an increase in curative health care expenditure and expected efficiency improvement after the 2006-reform has not taken place yet. Therefore, some further smaller reforms are outlined which should increase efficiency in years ahead.

\section{EU Health Care Expenditures Increase due to Ageing}

Most countries in the European Union are facing a structural worsening of their public budget as a result of the future development of the various age-related spending categories. Based on an EU calculation, total age-related public spending for the EU-27 is projected to increase by 4.6 percentage point of GDP over the period 2010-2060 (see EU (2009a)). Of this total, 2.3 percentage point is due to an increase in public pensions and 2.5 percentage point to an increase in health-care spending, including long-term care. (Note 1) In other words, public pensions account for only half of the rise in age-related spending, though they usually receive most of the attention in public discussions about ageing costs. Less attention is given to health care, despite the fact that it accounts for the other half of spending increases.

Those EU-wide averages hide substantial disparity among countries and among expenditure categories. For example, for public pensions, the most extreme cases are Greece, with an expected rise of 12.5 percentage point of GDP, and Luxemburg, with 15 percentage point of GDP in the period 2010-2060. However, in many countries retirement ages are being raised. For example, in the UK the standard pensionable age is scheduled to rise from 65 to 68 by 2044, in Germany from 65 to 67 by 2031, and in Greece - as an element of the Trojka package - the pension age will become 65 . In the Netherlands, the government recently approved a two-stage raise of the age at which people become eligible for a public pension from 65 to 67 . (Note 2) Therefore, in the next sustainability report these countries will be in a less worrying position with regard to pensions.

From a policy perspective it seems that health care reforms are more difficult, as equity issues and market failures must be solved. Projections on ageing show the importance of such a reform. The expenditures for health care are predicted to rise due to ageing by 2.5 percentage point of GDP in the EU between 2010 and 2060 (see Figure 1). The largest increase in the EU will take place in the Netherlands, with 5.5 percentage point of GDP. Germany is above average with a forecasted increase of 3 percentage point of GDP and, for example, Belgium and the United Kingdom are slightly below the average with a forecast of 2.4 and 2.3 percentage point of GDP.

$<$ Insert Figure 1 about here $>$

Within the broader concept of health care expenditure, one can distinguish between curative health care (such as hospitals, doctors and prescription medications), on the one hand, and long-term care (such as residential and nursing home care), on the other (see also Figure 1). For curative health care expenditure the Dutch increase of 0.9 percentage point of GDP is slightly below the EU average of 1.4 percentage point of GDP. However, the Dutch situation is especially exceptional for long-term care. The average EU increase for care expenditure is 1.3 percentage point of GDP. The costs of Dutch long-term care will raise by 4.5 percentage point of GDP between 2010 and 2060, more than three times the EU average.

For long-term care, the major difference between the Netherlands and most other EU-countries is the role of the state. Dutch long-term care is publicly organised and the benefits are relatively generous compared with those of other EU-countries. For example, in Germany an (elderly) person is only entitled to institutional care if home care and similar benefit forms are not adequate (see Heinicke and Thomsen (2010)). The amount of care provided depends on the actual needs of a person, but it is limited in value according to the assigned care level. (Note 3) Germans substitute formal care with informal family care; the chance that someone receives institutional care is 1.6 times higher in the Netherlands than in Germany (see Gradus and Van Asselt (2011)). Moreover, in the Netherlands the elderly have an individual legal right to public long-term care covering nursing, but also recreation and housing (see Schut and van den Berg (2010)). The Dutch personal responsibility and responsibility of the family for long-term care is very limited, and this is not sustainable in the long run. Therefore, in the Netherlands nowadays there is a large policy debate about long-term care.

\section{Technological Innovation Seems More Important}

Importantly, the EU study assumes that wages rise in line with the growth of labour productivity, which is assumed to converge to its historical average of 1.75 percent per year. (Note 4) Thus, the EC (2009a) projects public spending per cohort to increase in line with wages and thus with labour productivity. However, spending in the health-care sector may well rise more quickly. First, labour productivity in this sector may rise more slowly than in the rest of the economy, thereby putting upward pressure on wage costs (the so-called Baumol 
effect). Second, at the same time, technological innovations may boost spending in the curative sector. (Note 5) The EU projection is based on the essential assumption that technological innovation does not increase costs. (Note 6) However, in advanced economies technological innovations are a more important driver for expenditure increases than ageing as past experience shows. These effects may cause health-care spending to rise faster than projected by the EU. Projections by the IMF show that in advanced economies, public health care spending is projected to rise by an additional 3 percentage points of GDP over the next twenty years and by 6.5 percentage points of GDP over the next forty years (see IMF (2010)).

The largest increase is expected to take place in the USA, with 11.3 percentage point of GDP, the highest among the advanced economies (see Figure 2). Interestingly, the Netherlands is largely below the (weighted) average (Note 7), with a forecasted increase of 4.9 percentage point of GDP and, for example, Germany's forecasted increase is even lower, at 2.4 percentage point of GDP.

$<$ Insert Figure 2 about here $>$

For the coming twenty years, the average forecasted increase for the group of advanced economies is 3 percentage points of GDP. Around one-third of this increase would be due to the effects of population ageing. The remaining two-thirds would be due to excess growth, reflecting especially technological change, and to less important extent income growth and the Baumol effect. Also now, the USA is on top with a forecasted increase of 5 percentage points of GDP. For this period European public health care spending is also expected to rise substantially by two percentage points of GDP over the next twenty years. This stands in marked contrasts to the EU projections, which anticipate that public spending will rise by about 0.75 percentage point of GDP over the next twenty years (see EC (2009b)). Thus, IMF projections are two to three times higher than EU projections.

\subsection{Measure 1: demand-side reforms}

Nevertheless, the EU projections for public health care spending may still be realistic if several policy measures are taken. First, it is important that demand-side reforms are undertaken, so that an increasing share of care is financed privately rather than publicly. Since 1970, the share of public health care in total health care spending has risen by an average of 55 to 60 percent, exacerbating moral hazard problems (see IMF $(2010$, p. 7$)$ ). There is, thus, room for introducing demand-side reforms. Demand-side reforms can take two forms: more out-of-pocket expenditure or more private health care insurance. From an OECD overview it can be shown that out-of-pocket expenditure differs widely among EU-countries (see Figure 3).

$<$ Insert Figure 3 about here>

For example, compared with Spain or Italy, which have shares of more than twenty percent, the Dutch share is, at six percent, very low. In 2011, the Netherlands has no cost sharing for General Practitioners and maternity care assistance, and each patient is obliged to pay only the first $€ 165$ of health care costs per year. For the basic health care insurance a compulsory deductible of $€ 165$ is levied for all Dutch individuals aged 18 or older. Moreover, to offset current health care budget increases, in 2012 the compulsory deductible will be raised to 210 euros and a compulsory deductible for mental health care will be introduced.

Also the share of private insurance (at risk-rated premium) varies substantially among EU countries. Private insurance expenditures are almost absent in most Scandinavian countries and in Greece. In France, Germany, and to a more limited extent in the Netherlands (Note 8) and Spain, a substantial portion of health care is privately financed and insured.

$<$ Insert Figure 4 about here>

However, these demand-side policies can raise equity issues. In most countries, therefore, tax deductions for private medical expenses have been introduced, which offset the potential for reducing costs. Especially in the US context, tax expenditures are discussed, as they amount to 2 percent of GDP (see IMF (2010, p. 27)).

\subsection{Measure 2: market mechanism}

Second, measures which strengthen the role of the market mechanism are important as well. Hereby one can introduce competition between insurers and health care providers or introduce consumer choice of provider and insurer. An OECD study shows that for different countries the mix of market mechanisms is diverse (see Joumard et al. (2010)). (Note 9)

Joumard et al. (2011) show that Germany, Slovakia and the Netherlands rely extensively on market mechanism. In particular, these EU countries have introduced user choice for basic insurance coverage and patient choice of provider. However, a drawback of the market mechanism tends to be that it is difficult to maintain equity in access and in financing. Nevertheless, inequalities tend to be lower in Germany and the Netherlands, indicating 
that regulation and equalisation schemes can help mitigate the adverse effect of the market mechanism. (Note 10) In the Netherlands, the selective contracting clause, which allows health insurers to select health care providers and negotiate with hospitals and pharmaceutical companies, is considered to be a central pillar of the recent market-oriented health care reform. Nevertheless, fair competition is underpinned by risk-adjustment schemes between insurance pools with low- and high-risk populations. Therefore, the 2006 reform of curative health care and some further modifications of health insurance system will be discussed later on in more detail.

\subsection{Measure 3: budget caps}

Third, budget ceilings on several medical expenditures are used as an instrument to control budget expenditures, especially in periods of fiscal consolidation. In terms of efficiency, budget caps or ceilings can give mixed results. (Note 11) It should be noted that budget ceilings are a blunt instrument for restraining resources allocated to the public health care sector. In addition, budget constraint that is applied partially (for example only to in-patient care spending) can lead to expenditure increases in areas that are not controlled, such as out-patient care or pharmaceutical expenditure.

Joumard et al. (2010) shows that budgetary caps and controls have been widely used, in particular in countries as Sweden and the United Kingdom where health care delivery is mainly a responsibility of the public sector. Before the 2006 reform, the Netherlands strongly relied on budget ceilings and, currently, as the Dutch system has moved towards a market mechanism these instruments are less common. Nevertheless, as a consequence of current budgetary pressure there is some tendency to re-introduce these measures.

\subsection{Measure 4: public management}

Fourth, better public management and coordination is an important measure to improve efficiency as well. (Note 12) For example, a greater involvement of sub-national government in key health-care decisions can reduce expenditure growth if central oversight is maintained. Among OECD countries, Spain and Finland are clearly more decentralised than other OECD countries (see Joumard et al. (2010, p. 41)). In these countries the key health care spending issues including setting remuneration methods and financing new health care facilities are decentralised.

In addition, in the Netherlands and in Belgium general practitioners (GP) play an important role in controlling demand for more expensive hospital care. The gate keeping principle is one of the main characteristics of the Dutch and Belgium health care systems. It should be noted that the vast majority of Dutch people are registered with a GP and that hospital and specialist care (except for emergency care) and prescription medications are only accessible upon referral from the GP. However, there are considerable differences between general practices and therefore efficiency can still be improved (Schäfer et al. (2010, p. 191)). (Note 13)

\subsection{Measure 5: supply-side constraint and price controls}

Fifth, many reforms also contain supply-side constraints (Note 14) such as imposing regulatory controls on equipment and the health care workforce and delisting certain treatments. Restrictions on supply were used in the Netherlands by delisting certain treatments. Research by the OECD shows that these measures lower costs only slightly.

Price controls, (Note 15) on the other hand, have been ineffective, and the econometric results suggest that increased reliance on this measure actually increases excess growth. In some countries the impact of price controls can be eroded by supplier responses such as increasing volumes or directing patients to higher-cost services. Nevertheless, in the Netherlands real per capita expenditure on pharmaceuticals declined over the past five years.

\subsection{The impacts of the various measures}

Based on econometric methods, the IMF shows the average impact of the above-discussed five categories on health care spending in 2030. (Note 16)' (Note 17) The results suggest that reforms introducing the market mechanism and public management are powerful, yielding a reduction in excess cost growth of 0.5 and 0.4 percentage points of GDP (see Figure 5). (Note 18) (Note 19) This exercise also underscores the importance of budget caps, which can reduce spending by 0.25 percentage points. Finally, the simulated impact of demand-side reforms and supply constraint are small, but still positive.

$<$ Insert Figure 5 about here $>$

To summarise, market mechanism and public management have the most effective impact on increasing efficiency. Also, budget caps can be important in lowering costs, though they are a rather blunt instrument. Other 
instruments, such as supply side constraints and demand side reforms, are less effective, as they are often eroded by supplier responses or tax expenditures.

However, data limitations, uneven supply responses and the fact that various policy reforms are often implemented together make the identification of reform impacts difficult. (Note 20) Therefore, as also suggested by the IMF (2010, p. 18) it is important to use complementary methodology and discuss the impact of reforms in different countries. In addition, we will discuss the impact of the 2006 Dutch reform in more detail below.

\section{The 2006 Dutch Health Care Reform}

The main reason for the Dutch health care reform was that prior to 2006 the supply of health care services did not fit patient demand (see Schäfer et al. (2010)). This problem manifested itself in limited choice for patients, insufficient care and long waiting times for certain treatments. In addition, it had become clear that the existing hospital financing and capacity planning did not lead to efficiency, innovation and customer orientation (see RVZ (2003)). Furthermore, compared to other branches, the health care sector was lagging behind in implementing ICT innovations and solutions. Moreover, the Dutch health care insurance system, which consisted of public illness funds for persons below a certain income threshold (Note 21) and a voluntary private insurance for persons above this threshold, involved rather complicated rules. (Note 22) The main purpose of the reform, therefore, was to strengthen consumer demand. Efficiency was only a side effect. Also, cure expenditures in the Netherlands were boosted by technological innovation, as had been suggested by the IMF. Further measures are needed to limit cure expenditure increases (see below).

The Dutch reforms of 2006 were far-reaching, allowing private health insurance companies to compete in price and quality for the basic insurance (and voluntary insurance). This basic insurance includes elementary care for every Dutch citizen. The premium is a mixture between private and public elements and is financed by a flat-rate premium for each citizen plus an employer contribution. This flat-rate premium is neither income related nor risk rated and is set by insurers. (Note 23)' (Note 24) Children under the age of 18 are insured free of charges but have to be included in one of the parents' policies. (Note 25) Moreover, private insurers negotiate with hospitals and other suppliers about the price and quality of most health products.

To ensure universal access to health care insurance, some public guarantees exist. First, health insurance is mandatory for all citizens. Second, every citizen has unlimited admission to an insurer and may switch once a year; insurers may not refuse a citizen wishing to join their company. Third, lower incomes are compensated for an excessive premium by a health care allowance through the tax system. (Note 26) This means that the insurance system is separated from the income or the tax system - a crucial element of the Dutch system. In addition, to ensure the proper functioning of managed competition among health insurers, the allowance is not based on the actually (nominal) premium, but on a "standard premium" (i.e. the average of the premiums offered by insurers minus the compulsory deductible).

\subsection{The Dutch health care systems compared internationally}

In particular, recent international comparisons show that the Dutch health care system is more appreciated than the schemes of other countries (see also van Asselt et al. (2011)). For example, an international study of seven countries by Grol and Faber (2007) demonstrates that Dutch citizens are satisfied with the quality of care, affordability and functioning of the health-care system. The Euro-Canada Health Consumer Index 2010 also shows that the Dutch system is performing very well (Eisen and Björnberg, 2010). The Netherlands has the highest overall score, which is based on five subcategories: (i) patient rights and access to information; (ii) waiting times, (iii) patient outcomes, (iv) range and reach of services and (v) access to pharmaceuticals. The continental countries (the Netherlands, Germany, Austria, Switzerland and also France) all perform well, better than the Scandinavian countries (Denmark, Sweden, Norway and Finland), and far better than the Mediterranean countries and Eastern European countries (see Figure 6).

$<$ Insert Figure 6 about here $>$

Other patient-oriented studies confirm the Dutch top position, as shown by the poll of Harris Interactive (2008) and the annual survey 'Mirror, Mirror on the Wall' (Davis, Schoen and Stremikis, 2010). The Dutch health care system was included in this Anglo-Saxon comparison for the first time in 2009 and was ranked first.

\subsection{Continuing measures to increase efficiency}

Despite the reform, however, Dutch expenditure on curative health care has risen in recent years. In a recent analysis, the CPB (2011) shows that real health care expenditure rose by 4.4 percent annually between 2001 and 2010 and curative health care expenditure seems to have accelerated in 2008 and 2009 (see Figure 3.5. in CPB (2011, p. 28)). (Note 27) Interestingly, if they decompose health care expenditure, a large residue is found for 
this period, which gives an indication that technology have speed up. Based on these figures in the forecasted increase in health care expenditure in percentage point GDP in the Netherlands is 7.5 in 2040. It seems that the Netherlands has a double challenge in the health care sector: in the care sector where much reform is needed and the curative sector where more emphasis for efficiency is needed.

Therefore, it is important that many avenues are taken to increase efficiency in the curative sector. First, a further modification of the health insurance market is needed. In particular, the risk-equalisation scheme, which compensates insurers for high risks in their populations, should be modified by sharing fewer costs among insurers ex post. (Note 28) Nevertheless, placing more risk on insurers may give insurers more incentives for risk selection if the scheme does not properly compensate for pre-existing risk differences among the insured. The refinement of the risk-equalisation system is thus a delicate matter, but good working incentives are an essential part of a private insurance system to contain costs. Second, free negotiations between insurers and hospitals about prices and quality should be extended. (Note 29) Thereby, the selective contracting clause, which allows health insurers to select health care providers and negotiate with hospitals and pharmaceutical companies, should be used. Importantly, to prevent cost containment from dominating the delivery of quality, the reforms should be provided with better information on the quality of care provided in various hospitals. Accordingly, hospitals should bear more risk, including the possibility that they fail and go bankrupt. (Note 30) As a direct consequence of such a reform, hospitals will need more risk-bearing capital. This capital can be provided by private shareholders, as they have strong incentives to reduce the costs and to enhance the governance of hospitals. Nevertheless, to prevent cost containment from dominating the delivery of quality, the reforms should be complemented with better information on the quality of the care provided. Hereby, the hospital financing system (i.e. DBC system) should be reformed, as it is too complex for an adequate purchasing process. (Note 31) Third, the way care is organised determines the quality of care and hence the cost development. Cost development in health care has been found to be related to uncoordinated and fragmented care, such as overlapping diagnostics and lack of coordination between specialists. Such fragmentation is costly especially for chronic diseases such as diabetes, heart failure and chronic bronchitis. It is therefore better not to contract individual interventions but rather the so-called full cycle of care including self-management and prevention. With reduced complications, fewer references to expensive secondary care are needed and results would improve.

Health care reforms remain a long-lasting and difficult task. Nevertheless, the most important and politically sensitive reforms were implemented in 2006. According to OECD (2010), a coherent vision about the future of the health care system by the coalition partners in government was the main driver behind the success of the reform. Hereby, a unanimous recommendation by the Social Economic Council was supportive as well.

\section{Conclusions}

According to EU forecasts, ageing will increase public health care and pensions expenditure by 2.5 percentage point GDP by 2060, and therefore reform of pensions and health care systems are necessary in order to keep public finances sustainable. As IMF projections for health care in 2050 are much higher, at a maximum of 6.5 percentage point GDP, it is especially important that health care reforms should be implemented. These IMF projections include a stronger emphasis on technological innovations, and recent Dutch figures show that this type of expenditure has been accelerated particularly in the hospital sector. Therefore, it is important to implement cost-containing health care reforms.

Internationally-oriented research by the OECD shows that especially the market mechanism and public management are important with regard to containing costs (see Joumard et al. (2010)). Nevertheless, such reforms are difficult to implement, as equity issues have to be solved. As such, experience from abroad can be helpful. The Dutch example shows that consumer orientation and solidarity can best be organised in a private insurance system. Although a major reform of the Dutch health care system took place in 2006, it is important to complete the implementation of managed competition, thereby increasing efficiency. Moreover, a reform stage is needed for Dutch long-term care in which the responsibility of individuals and the family is boosted and the role of the government is minimised. It seems that the Netherlands has a double challenge for a ultimate reform in the care sector and for more efficiency in the cure sector.

\section{References}

Asselt, E. J., van Bovenberg, A. L., Gradus, R. H. J. M. \& Klink, A. (2011). Health Care Reforms in an Ageing European Society, with a Focus on the Netherlands. Brussels: Centre for European Studies. [Online] Available: http://www.thinkingeurope.eu/activities_cesevents_compro_2011_cda_2.asp 
CPB. (2011). Scenarios for health and care: part 1 report of the research programme. CPB Achtergronddocument bij CPB Policy Brief 2011/11. [Online] Available: http://www.cpb.nl/publicatie/omgevingsscenarios-voor-gez ondheid-en-zorg

Davis, K., Schoen, C. \& Stremikis, K. (2010). Mirror, Mirror on the Wall: How the Performance of the U.S. Health Care System Compares Internationally: 2010 Update. NY: Commonwealth Fund. [Online] Available: http://www.commonwealthfund.org/ /media/Files/Publications/Fund\%20Report/2010/Jun/1400_Davis_Mirror_ Mirror_on_the_wall_2010.pdf

Eisen, B. \& Björnberg, A. (2010). Euro-Canada Health Consumer Index 2010. Frontier Centre for Public Policy: Winnipeg/Canada. [Online] Available: http://www.fcpp.org/publication.php/3285

European Commission. (2009a). Sustainability Report 2009. European Economy Nr. 9. [Online] Available: http://ec.europa.eu/economy_finance/publications/publication15998_en.pdf

European Commission. (2009b). 2009 Ageing Report: Economic and Budgetary Projections for the EU-27 Member States. (2008-2060). European Economy Nr. 2. [Online] Available: http://ec.europa.eu/economy_financ e/publications/publication_summary14911_en.htm

Gradus, R. H. J. M. \& van Asselt, E. J. (2011). Long-Term Care Compared in the Netherlands and Germany. ESB. 96, 202-204. [Online] Available: http://esbonline.sdu.nl/esb/esb/archief/abbo1/toonartikel1.jsp?di=599343

Grol, R. \& Faber, M. (2007). Survey Research Among Consumers and Patients in 7 Countries. Nijmegen: Centre for Quality of Care Research (WOK), UMC St Radboud. [Online] Available: http://www.wokresearch.nl/UserFil es/Docs/product_41.pdf

Heinicke, K. \& Thomsen, S. L. (2010). The Social Long-Term Care Insurance in Germany: Origin, Situation, Threats, and Perspectives, Mannheim: ZEW Discussion Paper No. 10-012. [Online] Available: ftp://ftp.zew.de/p ub/zew-docs/dp/dp10012.pdf

IMF. (2010). Macro-Fiscal Implications of Health Care Reform in Advanced and Emerging Economies. Washington: IMF staff paper. [Online] Available: http://www.imf.org/external/np/pp/eng/2010/122810.pdf

Joumard, I., André, C. \& Nicq, C. (2010). Health Care Systems: Efficiency and Institutions, OECD Economics Department Working Papers, No. 769. Paris: OECD. [Online] Available: http://ideas.repec.org/p/oec/ecoaaa/76 9-en.html

Nelson, A. L., Cohen, J. Th., Greenberg, D. \& Kent, D. M. (2009). Much Cheaper, almost as good: Decrementally cost-effective medical innovation. Annals of Internal Medicine, 151, 662-669. [Online] Available: http://www.annals.org/content/151/9/662.full.pdf+html?sid=ae891303-7887-427f-997b-6a82cf7c8a27

OECD. (2010). Making Reform Happen. Paris: OECD. [Online] Available: http://www.oecd.org/site/0,3407,en _21571361_46134848_1_1_1_1_1,00.html

Raad voor de Volksgezondheid en Zorg (RVZ) (2003). Acute Care. Zoetermeer: RVZ. [Online] Available: http:// www.rvz.net/publicaties/bekijk/acute-zorg

Schäfer, W., Kroneman, M. W., Boersma, M., van den Berg, G., Westert, W. D. \& van Ginneken, E. (2010). The Netherlands: Health System Review. Health Systems in Transition, 12(1).

Schut, F. \& van den Berg, B. (2010). Sustainability of Comprehensive Universal Long-Term Care Insurance in the Netherlands, Social Policy \& Administration, 44, 411-435. http://dx.doi.org/10.1111/j.1467-9515.2010.0072 $1 . \mathrm{x} / \mathrm{pdf}$

\section{Notes}

Note 1. In this forecast, expenditure on unemployment benefits is projected to fall from 0.8 percentage point of GDP in 2007 to 0.6 percentage point of GDP in 2060. This reduction is mainly driven by the assumption that unemployment rates in all countries with unemployment rates above the EU-15 average would converge to the EU-15 average by 2020 due to an ageing society.

Note 2. In particular, the age at which people can start to draw their state old-age pension would be raised by one year in 2020 and by another year in 2025, such that the state pension age would be 67 by that time.

Note 3. Individuals can choose between institutional care and two home care programmes: cash benefits (Plegegeld) or agency services in kind (Sachleistung). Cash benefits only amount to about half of the monetary value of agency services (see Heinicke and Thomsen (2010, p. 13)). 
Note 4. Together with this productivity growth, the development of employment then determines economic growth. As a result of declining labour supply, GDP growth is forecasted to average 1.3 percent per year by 2040.

Note 5. Of course, most technological innovations will improve health care and life expectancy as well. According to a micro study, $72 \%$ of innovations improves the revenues of health care in higher life expectancy and improved health care (see Nelson et al. (2009)).

Note 6. The EU projections do not take into account technological innovation, but account, however, for the so called smaller Wagner-effect, which implies that higher welfare raises the share of income spend on health. In particular, the EU assumes that a rise of $1 \%$ in income results in a $1.1 \%$ rise in spending on health care per capita for each age group.

Note 7. Weighted average is based on GDP at Purchasing Power Parity.

Note 8 . In the Netherlands, the basic insurance is also carried out by private insurance companies. However, the premium is neither income- nor risk-related and is therefore not included in Figure 4.

Note 9. The indicator 'market mechanism' is based on the following sub-indicators: choice of insurers, insurer levers, user information, private provision and choice among providers (see $\operatorname{IMF}(2010$, p. 21)).

Note 10. Health inequality is measured by the standard deviation in mortality ages for the population older than 11. The Netherlands has the lowest health inequality of all OECD countries; Germany is eighth (see Joumard et al. (2010, p. 12)).

Note 11. The indicator budget caps is based on the following sub-indicators: budget constraint and central government oversight (see IMF (2010, p. 21)).

Note 12. The indicator public management and coordination is based on the following sub-indicators: gate-keeping, sub-national involvement and delegation (see IMF (2010, p. 21)).

Note 13. In ageing societies it is important to create a health care chain with general practitioners, nurse practitioners and some specialists for those suffering from, for example, Parkinson's disease, and experiments show that these are cost-containing as well.

Note 14. The indicator supply constraints is based on the following sub-indicators: regulation of the workforce and equipment and the setting of priorities (see IMF (2010, p. 21)).

Note 15. The indicator price controls is based on the following sub-indicators: regulation of providers' prices and regulation of prices paid by third-party payers (see IMF (2010, p. 21)).

Note 16. The econometric analyses uses recently compiled OECD data on key indicators of health care systems to evaluate the relationship between these characteristics and the growth of public health care spending. These 17 indicators were used in the principal component analysis in the OECD report to create four composite indices, and these were included in the econometric analysis. To estimate the impacts of these reforms on the increase in public health care expenditure (corrected for ageing), a one-unit increase is applied to each of the 17 variables underlying the four composite indices (see appendices of IMF (2010)).

Note 17. The average of ECG estimates from country-fixed effects are 0.8 percent and 1.7 percent for the periods 1980-2008 and 1995-2008, and these results are extrapolated using GDP growth in 2010-2030 (see IMF (2010, p. 49-50)).

Note 18. This figure shows the estimated impact on excess costs growth of moving up one unit in any given OECD index, keeping all other indices fixed. The OECD indices range from a score of zero to six.

Note 19. According to personal correspondence with Boaping Shang of the IMF, this are the rounded estimates.

Note 20. As also pointed out by Joumard et al. (2010, p. 41-43) using composite indicators can raise tricky issues as well and, therefore, the empirical results should be interpreted with caution.

Note 21. In 2005, this threshold was $€ 29,000$ per year.

Note 22. To compensate the illness fund for the effects resulting from a large influx of elderly persons, those privately insured were obliged to contribute to the coverage of the disproportionately high costs of the illness fund scheme.

Note 23. The nominal premium was on average around 1100 per year in 2009. 
Note 24. In 2009, the employer contribution amounts to 6.9 percent of wage income (with a ceiling of $€ 2,233$ per year) for employees and social security recipients. For the self-employed and pensioners the contribution was $4.8 \%$ of income (with a ceiling of $€ 1,554$ per year) in 2009 .

Note 25. The nominal premium for children is paid by the government and amounted to 2.2 billion euros in 2007.

Note 26. About one in three adults received this allowance in 2006, ranging from $€ 24$ to $€ 1461$ (which was the maximum for families in 2007).

Note 27 Table 3.3. gives a decomposition of real growth of 4.4 percent between income (2.0), demographics (0.7) and a residue (1.7).

Note 28. Since health care insurers cannot yet influence the expenditure for all costs, ex post compensation mechanisms were established in 2006.

Note 29. At the introduction in 2005, this share was $10 \%$ of all treatments. By 2008 this share had increased to $20 \%$ and in 2009 to $34 \%$. The Rutte cabinet has proposed plans to raise it to $70 \%$.

Note 30. Currently, hospitals are non-profit institutions, as a for-profit motive is not allowed. Since 2008, however, a few pilots have started that have allowed paying out part of the profit to the shareholders. These experiments are, however, restricted by the government in order to guarantee public interests. The current Rutte cabinet has announced that in general, hospitals should be allowed to generate profits.

Note 31. The government has announced plans to decrease the number of DBCs from 30,000 to 3,000 and to strengthen the relationship between DBCs and quality.

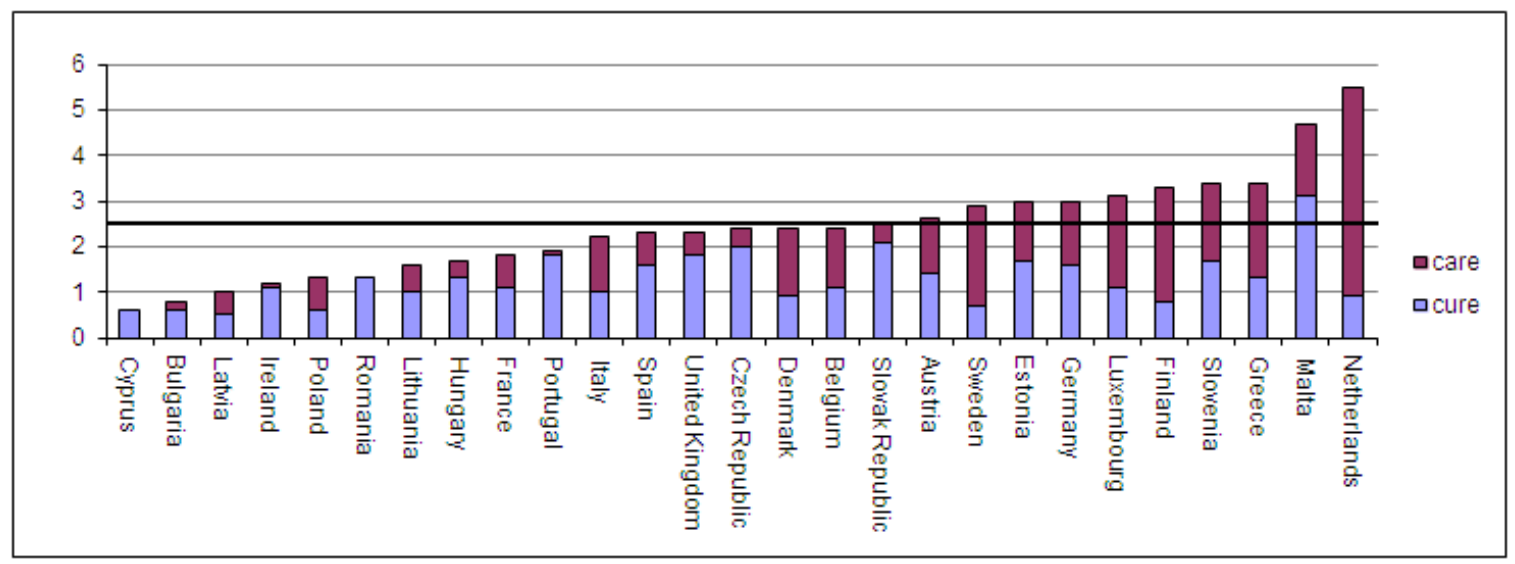

Figure 1. Forecasted increase in health care expenditures 2010-2060 by EU (\% GDP)

Source: own presentation based on EC (2009a, p. 29) 


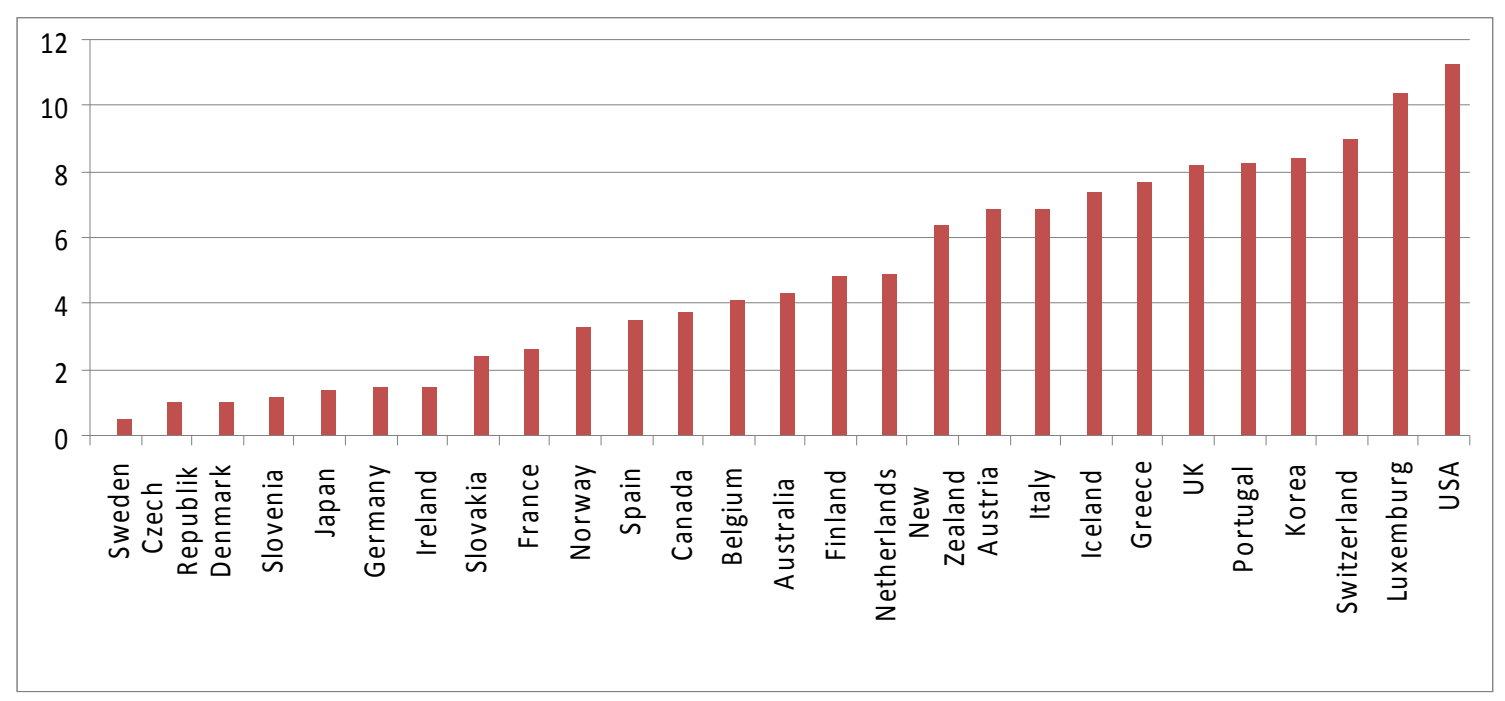

Figure 2. Forecasted increase in health care 2010-2050 by IMF (\% GDP)

Source: own presentation based on IMF (2010, p. 57)

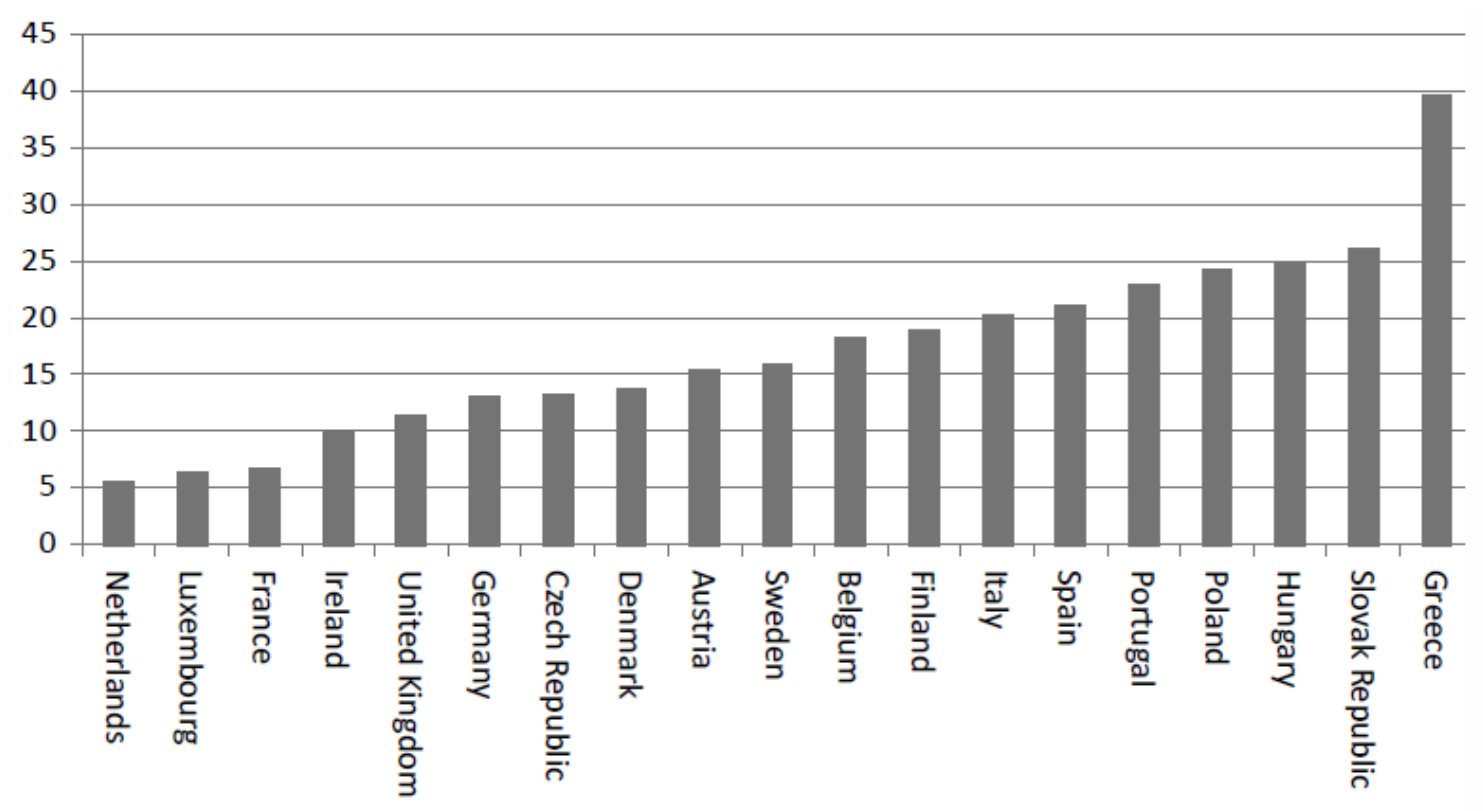

Figure 3. Out-of-pocket expenditures (\%) as share of 2007 health care expenditures

Source: OECD health data 2009 


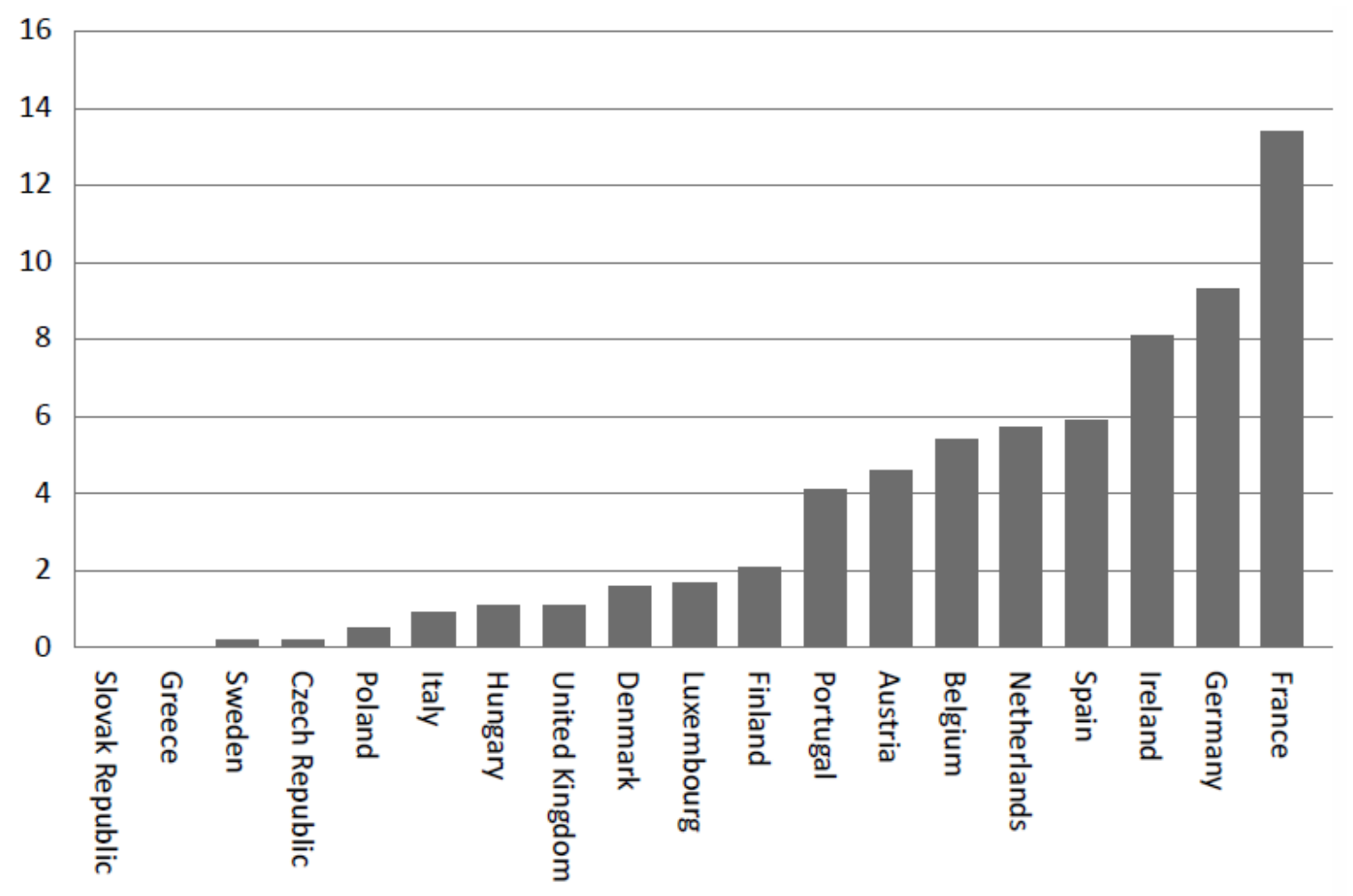

Figure 4. Private health insurance (and risk-rated premium) (\%) as a share of total health expenditures, 2007 Source: OECD health data 2009

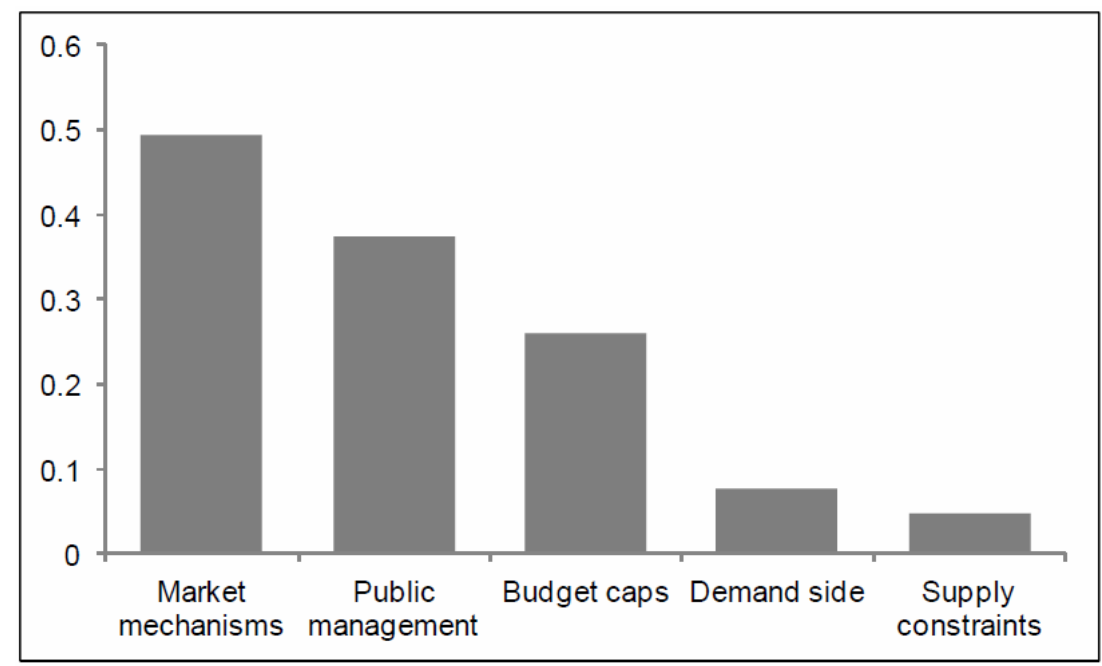

Figure 5. Average impact of different measures on health care spending (Note 32)

Source: IMF (2010, p. 31) 


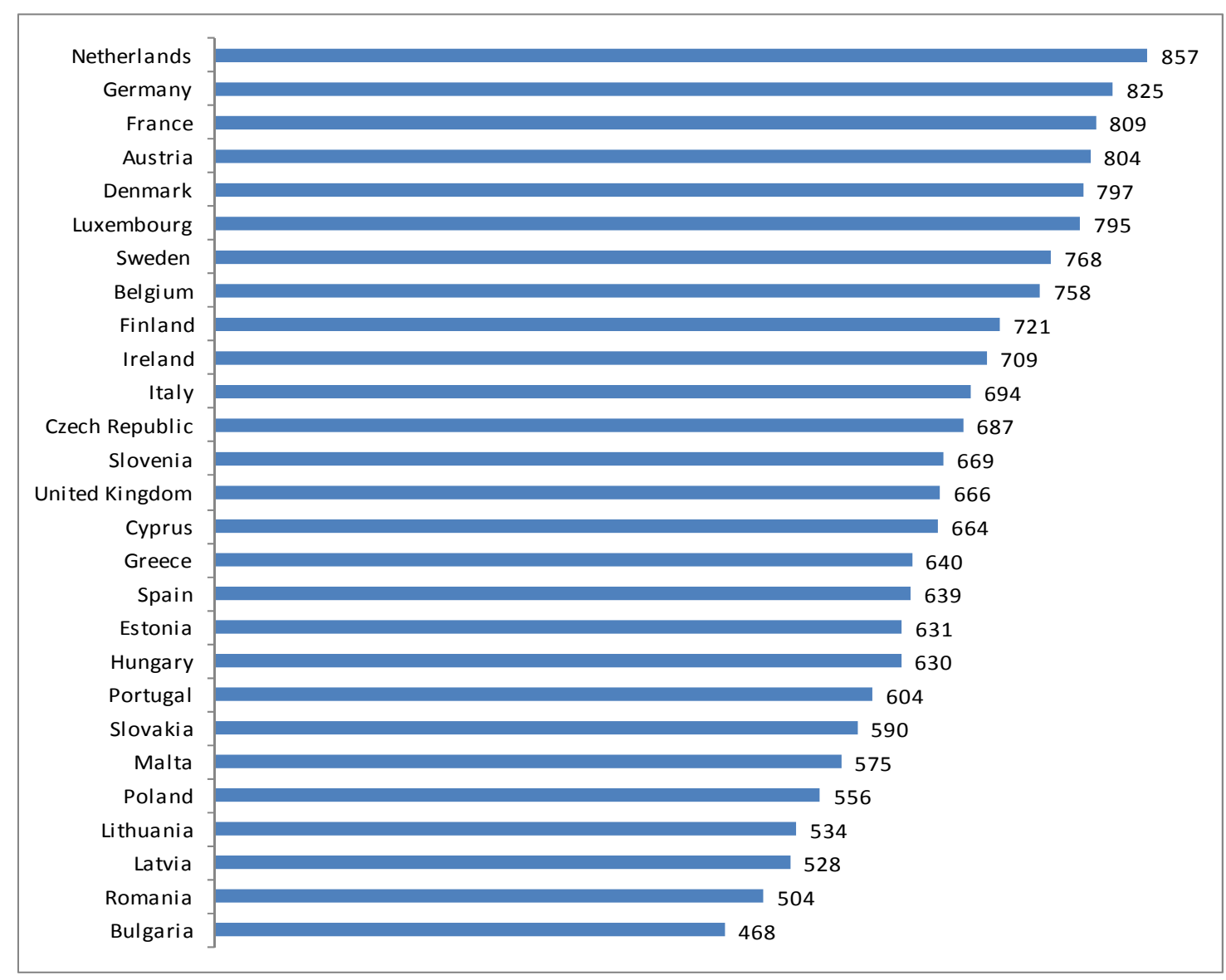

Figure 6. Total scores in the Euro-Canada Health Consumer Index

Source: Eisen and Björnberg (2010) 